\title{
Nodal user's demand response based on incentive based programs
}

\author{
Nestor GONZÁLEZ-CABRERA ${ }^{1,2}$, Guillermo GUTIÉRREZ-ALCARAZ ${ }^{2}$
}

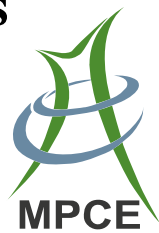

\begin{abstract}
This paper describes a practical approach to identify nodal price compensation payment for nodal consumers willing to reduce their energy consumption (consumers' demand response). The implementation of a nodal reliability service pricing is based on contingency assessment of $N-2$ order for transmission lines. A representative annualized demand curve is used to reflect the system's operation condition by seasons. Such curve is used to access the nodal reliability impact trough a whole year in order to determine back-payments (incentive payment) to users for service interruption. The IEEE_RTS 24 nodes system is used to implement the proposed approach.
\end{abstract}

Keywords Nodal demand response, Demand side management, Reliability assessment, Incentive based programs (IBP)

\section{Introduction}

Electricity restructuring, also called deregulation, enhances competition among energy suppliers and gives the consumer the ability to choose an electric supplier based on a

CrossCheck date: 18 November 2016

Received: 20 August 2016/ Accepted: 18 November 2016/Published online: 6 January 2017

(C) The Author(s) 2017. This article is published with open access at Springerlink.com

$\triangle$ Nestor GONZÁLEZ-CABRERA

nestorgc@ieee.org

Guillermo GUTIÉRREZ-ALCARAZ

ggutier@itmorelia.edu.mx

1 Instituto Tecnológico Superior de Irapuato, Irapuato 36620, Mexico

2 Instituto Tecnológico de Morelia, Morelia 58120, México preferred level of reliability. Nodal pricing has been developed to represent the operational cost of the nodes in an electric grid. Due to the close relationship between nodal pricing and nodal reliability, it is now possible to have nodal prices closely reflecting reliability performance [1]. A technique to evaluate nodal prices and nodal reliability is reviewed in [2]. The authors present several models for transmission and generation outages and their effects on nodal prices. A differentiated service based on reliability price is studied by [3-7]. In [8], an evaluation of nodal reliability based on the load point (LP) uses a reliability network equivalent (RTE) technique to represent each service provider separately. In [9], the RTE technique has been improved to include the effect of intermittent renewable sources in the generation system.

To enhance nodal reliability, demand response (DR) programs have been implemented using demand side management (DSM). A load direct control (LDC) to disconnect strategic loads belonging to users is proposed in [10]. The authors propose a stochastic optimization model to reduce the total cost of operation, based on the efficient use of traditional and renewable sources of energy. The authors also consider nodal reliability and customers' willingness to pay for it. Several novel LDC schemes within DR programs have been developed in [11]. The algorithms proposed minimize network congestion and reduce the existing gap between energy generation capacity and demand. In [12], heating, ventilation, and air conditioner are controlled remotely using DR schemes, or by managing energy-interruptible-service contracts to guarantee system reliability. The contracts provide incentives for customers willing to be interrupted in any period of time with prior notification. An active management model that integrates a curtailment load mechanism is introduced in [13]; the mechanism uses different strategies based on the energy management model of the distribution system. 
A model for evaluating contracts with interruptible loads is described in [14], and a program for managing interruptible loads considering distinct generation contingencies is formulated. The integration of renewable energy generation schemes into interruptible contracts is studied in [15]. In [16], a scheme for incentive DR programs that enables the DR provider to compute individual demand curtailments and DR rewards while preserving customers' privacy. An energy efficient optimization model which offers incentives to end users curtailing their energy use during times of peak demand is reported in [17]. To benefit a customer by minimizing electricity cost, the proposed model optimally schedules the electricity consumption of different household appliances in a dynamic pricing environment. An implementation of DR to improve network reliability proposed in [18] uses a non-linear mathematical model of the incentive DR programs to identify the most reliable and conservative responsive model. An incentive mechanism to promote the participation of distribution companies in DR energy efficiency programs is proposed in [19]. The model allows studying the effect of the payments scheme incorporating uncertainty.

Many recent nodal analysis studies have been assessing reliability issues using DR programs to boost system performance on all nodes. The studies, however, do not consider, or are limited by, the following factors: 1) unknown type of participants in the DR programs; 2) assuming or considering an ideal amount of interruptible loads without previous knowledge of nodal reliability and/or interruption capacity by node; and 3) considering only one period of time (generally, peak period), or three clusters (one around a demand peak; another off-peak and one in a valley). To address the limitations above, this paper develops a mechanism for obtaining high reliability nodal prices and compensating for nodal interruption, using incentive based programs (IBP) based on DR. The nodal identification of interruptible loads is based on the expected nodal energy not supplied (ENENS) and a structural decomposition of the system reserves in order to improve the loss of load probability (LOLP) reliability index. The method sets both a tariff for high nodal reliability performance and a "money back" payment incentive for interruptible loads. Thus, it offers users on DR programs a transparent, simple way to calculate their expected amount of reimbursements based on their level of service interruptions. The remainder of this paper is organized as follows. Section 2 describes the mathematical modelling. Section 3 describes methodology of the estimation of a representative annual demand curve. Section 4 describes the experimental section with an IEEE_RTS 24-node system. Section 5 discusses the results of applying the methodology, and offers suggestions for future research.

\section{Mathematical modelling}

\subsection{Reliability assessment}

This section describes the reliability evaluation of the component system. The unavailability $\left(U_{c}\right)$ of the element $c$ is computed by (1):

$U_{c}=\left(\frac{\lambda_{c}}{\mu_{c}}\right)$

where $\lambda_{c}$ is the failure rate of the connected element and $\mu_{c}$ is the number of annual repairs of such element. The availability of component $A_{\mathrm{c}}$, is calculated by the following equation:

$A_{c}=1-U_{c}$

The probability for the occurrence of the $j^{\text {th }}$ state can be calculated as follows:

$p^{j}=\prod_{c=1}^{d} U_{c} \prod_{c=d+1}^{N_{c}} A_{c}$

The nodal energy not supplied (NENS) for each contingency is calculated as:

$N_{E N S_{b}^{j}}=V_{G_{b}^{j}}$

where $V_{G_{b}^{j}}$ is the representation of NENS that relieves the over load due to $j^{\text {th }}$ contingency.

The ENENS is calculated as the expected value of NENS for a period of time to be defined within the analysis for the total number of states (TNS, goes from state 0 to $N-2$ ) and, it is described by (5):

$E_{N E N S_{b}}=\sum_{j=1}^{T_{N S}} p^{j} \times N_{E N S_{b}^{j}}$

The expected energy not supplied (EENS) is the sum of all nodes into the system with ENENS multiplied by the period of time $T$ to be considered, is calculated as:

$E_{E N S}=\sum_{b=1}^{N_{b}} E_{N E N S_{b}} \times T$

The index LOLP measures the probability that an energy-demand event on the system will exceed the transmission line capacity during a given period [20]:

$L_{O L P_{i}}=\frac{1}{T} \sum_{j=1}^{T_{N S}} p^{j} u\left(E_{A}(j)-E_{D i}(j)\right)$

where $E_{A}(j)$ is the available energy for the $j^{\text {th }}$ contingency; $E_{D i}(j)$ is the energy demand at the $i^{\text {th }}$ node for the $j^{\text {th }}$ contingency; and $u\left(E_{A}(j)-E_{D i}(j)\right)$ is the binary function defined as: 
$u\left(E_{A}(j)-E_{D i}(j)\right)=\left\{\begin{array}{cc}1 & E_{A}<E_{D i} \\ 0 & E_{A}>E_{D i}\end{array}\right.$

It is 1 if the available energy cannot cover the nodal demand and, it is 0 if the energy is satisfied for the $j^{\text {th }}$ contingency.

The maximum deliverable nodal capacity (MNDC) defined in [21], as the difference between nodal load and the NENS, is calculated as:

$M_{D N C_{b}^{j}}=P_{\text {Load }_{b}}-N_{E N S_{b}^{j}}$

where $P_{\text {Load }}$ is the load of bus $b$ and $N_{E N S^{j}}$ is the nodal energy not supplied of the contingency $j$ of bus $b$.

The expected value of MNDC is calculated as:

$M_{E D N C_{b}}=\sum_{j=1}^{N_{T E}} M_{D N C_{b}^{j}} \times p^{j}$

\subsection{Optimal power flow}

The problem to be solved by the SO is: for each state $j$ and any period of time $t$, is to determine the classification of interruptible loads by node. This is done as follows: the function that minimizes the total costs of producing active power is given by:

$\min =\sum_{i=1}^{N_{g}} C_{i, t}\left(p g_{i, t}\right)+\sum_{i=1}^{N_{g}} C_{R_{i, t}}\left(r_{i, t}\right)+\sum_{b=1}^{N_{b}} V_{O L L_{b, t}}$

Subject to

$\sum_{i=1}^{N_{g}}\left(p g_{i, t}+r_{i, t}\right)-\sum_{b=1}^{N_{b}}\left(P d_{b, t}+V_{G_{b, t}}\right)=\sum_{m \in \Omega_{i}} \frac{\theta_{i}-\theta_{m}}{X_{i m}}$

$\forall i=1,2, \cdots, N_{g}, \quad \forall b=1,2, \cdots, N_{b}, \quad \forall \Omega_{i}=1,2, \cdots, N_{l}$

$p g_{i}^{\min } \leq p g_{i, t} \leq p g_{i}^{\max } \quad i=1,2, \cdots, N_{g}$

$P_{i m, t} \leq P_{i m}^{\max } \quad \forall \Omega_{i}=1,2, \cdots, N_{l}$

$V_{G_{b, t}} \leq V_{G_{b, t}^{\max }} \quad \forall b=1,2, \cdots, N_{b}$

$\left\{\begin{array}{l}0 \leq r_{i, t} \leq \min \left(r_{i, t}^{\max }, \Delta_{i, t}\right) \\ \Delta_{i}=\mathrm{AGC}, \mathrm{R} 10, \mathrm{R} 30\end{array} \quad i=1,2, \cdots, n_{g}\right.$

$p g_{i, t}+r_{i, t} \leq p g_{i}^{\max } \quad i=1,2, \cdots, N_{g}$

$0 \leq p g_{i, t}^{+} \quad i=1,2, \cdots, N_{g}$

$p g_{i, t-1}+p g_{i, t} \leq p g_{i, t}^{+} \quad i=1,2, \cdots, N_{g}$

$p g_{i, t}^{+} \leq r_{i, t}^{+} \leq R_{i, t}^{\max +} \quad i=1,2, \cdots, N_{g}$

$0 \leq p g_{i, t}^{-} \quad i=1,2, \cdots, N_{g}$ $p g_{i, t-1}+p g_{i, t} \leq p g_{i, t}^{-} \quad i=1,2, \cdots, N_{g}$

$p g_{i, t}^{-} \leq r_{i, t}^{-} \leq R_{i, t}^{\max -} \quad i=1,2, \cdots, N_{g}$

$-\Delta_{i, t}^{-} \leq p g_{i, t} \leq \Delta_{i, t}^{+} \quad i=1,2, \cdots, N_{g}$

where $C_{i, t}\left(p g_{i, t}\right)$ is the curve of the total cost of energyproduction at node $i ; C_{R_{i, t}}\left(r_{i, t}\right)$ is the curve of the total cost of energy-reserve generation at the $i^{\text {th }}$ node; $V_{G_{i, t}}$ is the virtual energy-generation that represents the amount of energy not supplied at the $i^{\text {th }}$ node; $p g_{i}^{\min }$ and $p g_{i}^{\max }$ are the nominal minimum and maximum of active power at the $i^{\text {th }}$ generator, respectively; $r_{i, t}^{\max }$ is the maximum reserve of active power of the $i^{\text {th }}$ generator; $\Delta_{i, t}$ is the physical ramp of the $i^{\text {th }}$ generator for each reserve system AGC, R10 or $\mathrm{R} 30 ; r_{i, t}$ is the reserve of active power of the $i^{\text {th }}$ generator; $p g_{i, t}^{+}$is the power generation of ramp-ups for generator $i$; $p g_{i, t}^{-}$is the power generation of ramp-downs of the $i^{\text {th }}$ generator; $r_{i, t}^{+}$is the reserve of active power for generating ramp-ups using the $i^{\text {th }}$ generator; $r_{i, t}^{-}$is the reserve of active power for generating ramp-downs using the $i^{\text {th }}$ generator; $R_{i, t}^{\max +}$ is the maximum reserve of active power for generating ramp-ups using the $i^{\text {th }}$ generator; $R_{i, t}^{\max -}$ is the maximum reserve of active power for generating ramp downs using the $i^{\text {th }}$ generator; $\Delta_{i, t}^{-}$is the physical limit of active power for generating ramp-downs using the $i^{\text {th }}$ generator; $\Delta_{i, t}^{+}$is the physical limit of active power for generating ramp-ups using the $i^{\text {th }}$ generator; $P_{i m}^{\max }$ is the maximum power flow from the $i^{\text {th }}$ node to the $m^{\text {th }}$ node; and $P_{i m, t}$ is the power flow from the $i^{\text {th }}$ node to the $m^{\text {th }}$ node; $N_{g}$ is the number of generators; $N_{b}$ is the number of buses and $N_{l}$ is the number of lines.

Equation (11) is the objective function, constraint (12) represents the nodal balance of active power, constraint (13) represents the minimum and maximum generation limits for each unit, constraint (14) is the maximum power flow of each transmission line, constraint (15) is the limit of the virtual generation, constraint (16) is the limit of the active power reserve of the contributing generators, constraint (17) is the active power of each generator's reserve from exceeding each generator's maximum output, constraints (18) and (19) represent the limits of the upward ramps of the dispatched generators, constraint (20) is the power output of the ramp ups for the dispatched generators, constraints (21) and (22) are the limits of the ramp downs of the dispatched generators, constraint (23) the output power of the generator ramp-downs does not exceed the maximum active power ramp-down of the system reserve, constraint (24) represent the physical limits of the ramps of the dispatched generators. 


\subsection{Nodal prices}

Assuming that all inequality constraints are initially inactive, to simplify the calculation of nodal prices, the Lagrangian function $L(X, \lambda, \mu)$ can be written as:

$$
\begin{aligned}
& L(X, \lambda, \mu)= \\
& {\left[\sum_{i=1}^{N_{g}} C_{i, t}\left(p g_{i, t}\right)+\sum_{i=1}^{N_{g}} C_{R_{i, t}}\left(r_{i, t}\right)+\sum_{b=1}^{N_{b}} V_{O L L_{b, t}}\right]} \\
& -\left[\sum_{i=1}^{N} \lambda_{p i}\left(\sum_{i=1}^{N_{g}} p g_{i, t}+\sum_{i=1}^{N_{g}} r_{i, t}\right)\right] \\
& -\left[\sum_{i=1}^{N} \lambda_{p i}\left(\sum_{b=1}^{N_{b}} P d+\sum_{b=1}^{N_{b}} V_{G}-\sum_{m \in \Omega_{i}} \frac{\theta_{i}-\theta_{m}}{X_{i m}}\right)\right]
\end{aligned}
$$

The first order conditions are:

$$
\left\{\begin{array}{l}
\frac{\partial L}{\partial p g_{i, t}}=C_{i, t}-\lambda_{p i}=0 \\
\frac{\partial L}{\partial r_{i, t}}=C R_{i, t}-\lambda_{p i}=0 \\
\frac{\partial L}{\partial \lambda_{p i, t}}=\left(p g_{i, t}+r_{i, t}-P d_{i, t}+V_{G_{i, t}}-\frac{\theta_{i, t}-\theta_{m, t}}{X_{i m, t}}\right)=0
\end{array}\right.
$$

The nodal price for all estates is given by the equilibrium of energy-demand for the normal operating state:

$\rho_{i}^{j}=\frac{\partial L^{j}}{\partial \lambda_{p i}^{j}}$

where $\rho_{i}^{j}$ is the nodal price of real power in the $j^{\text {th }}$ state.

The nodal reference-price is the nodal-price times the probability of the occurrence of the state $N-0$ [2]:

$\rho_{i}^{R}=\rho_{i}^{0} p^{0}$

The nodal price for high reliability (HR) users is the expected nodal price (only up to $N-2$ contingencies are considered) plus the nodal reference-price. This is computed as follows:

$\rho_{i}^{H R}=\rho_{i}^{R}+\sum_{j=1}^{N-2} \rho_{i}^{j} p^{j}$

The incentive nodal bonus (INB) [21], i.e. payment for load if curtailment is required, is the difference between the nodal reference-price and the nodal price of the $j^{\text {th }}$ state associated with the node having a curtailment load. This is computed as:

$I_{N B_{i}}=\sum_{j=1}^{N_{T S}} p^{j}\left(\rho_{i}^{j}-\rho_{i}^{0}\right) \quad \forall j \in L_{C_{i}}$

\subsection{Reserve system requirements}

The operation of the reserve system (AGC, R10, R30) is characterized by its speed of response (starting time and ramp rate), duration of response, frequency of use, use direction (up or down), and type of control. Some operating reserves are used to respond to routine variability of the generation or the load. Within accordance with NERC [22], the energy-reserve for a certain event (contingencies/ outage elements interconnected) is classified by contingency reserve (AGC, R10, R30), i.e. instantaneous or ramping reserve (build-up or non-instantaneous). The contingency reserve generation capacity is available to instantly balance the generation and demand of active power during rare events (sudden outage of lines and transformers) that are more severe than the imbalances by monitoring demand. Ramping reserve $\left(r_{i}^{+}\right.$or $\left.r_{i}^{-}\right)$is the generation capacity available for assistance in balancing active power during non-frequent events that are more severe than the balancing required during normal conditions; it is used to correct non-instantaneous imbalances. The instantaneous event considers the primary reserve (AGC), as some portion of the system reserve that can automatically respond to the contingency to ensure that the maximum deviation allowed of the system frequency $(60 \mathrm{~Hz})$ is not surpassed. Also, the balance in the load must be maintained as soon as the event is controlled. The primary reserve responds instantly following the event to avoid extreme frequency deviations that can cause damage or involuntary load shedding. Primary reserve can be supplied by any governor generator system that can quickly respond and maintain the response as the system frequency $(60 \mathrm{~Hz}$ by more than $+/-0.036 \mathrm{~Hz})$ decreases. Then, secondary reserve is deployed to return the frequency to its scheduled setting. Finally, tertiary reserve assists in the replacement of primary and secondary reserves that were used for the outage of elements in the system. The typical time-response is 10 seconds for the primary reserve and, 10 to 30 minutes for the secondary and tertiary reserves, respectively [23].

\section{Methodology}

This section briefly describes the methodology for estimating nodal DR, based on the ENENS decomposition, as well as nodal price compensation payment, incentive based programs (IBP). Special emphasis is placed on obtaining the load duration curve (LDC) in a detailed way, in order to implement the ramps for better short-term planning. 
The methodology is summarized in the next steps:

1) The estimation of a representative annual demand curve is used to define the total number of days to be analyzed (4 days/year).

2) An hourly OPF is executed for $j=0: N-2$ contingencies for each day.

3) The NENS and MNDC for each contingency is identified.

4) The ENENS, MENDC, and the INB are computed.

The following considerations are made:

1) The ENENS is the main index considered for reliability assessment, due to the fact that it is one of the most popular reliability indexes used for evaluating contingencies.

2) Under the current market environment, generation companies (GenCos) are responsible for full compliance to their generation contracts; therefore, it is possible to have reserve generation agreements with others GenCos. In such a way that no contingencies of generation are considered.

3) Up to $N-2$ simultaneous outages of transmission lines are considered, for the ENENS computation.

4) A DC-OPF is used, due to advantages of an AC based model [24].

\subsection{Estimation of representative annual demand curve}

The LDC is a simple tool for solving problems related to the design and operations of electric systems. The LDC curve depicts the energy demand arranged in clusters from high to low demand against the respective time-intervals. The flexibility of grouping energy in classes allows the amount of data to be reduced, i.e. reducing the computational burden. If class grouping is not used, all data set must be employed, i.e. 8760 data points per year.

An undesirable effect of demand class grouping is the lack of accuracy in estimating the ramp-ups and rampdowns of the system's energy reserves. Demand class grouping, can also lead to errors in estimating the real energy demand at the nodes of the system by reducing the seasonal (summer, winter, weekend days, and holidays) variability of such demand. Figure 1a shows that for some weekdays, weekend days and winter-days, the lowest energy consumption is $2200 \mathrm{MW}$, whereas for some summer-days or regular week days the energy consumption is higher $(2350 \mathrm{MW})$. Figure $1 \mathrm{~b}$ depicts an expanded detail of Figure 1a. It is necessary to correctly evaluate system reliability by considering the length of the time-intervals during which all of the system's energy reserves must be available, i.e. temporal variability.

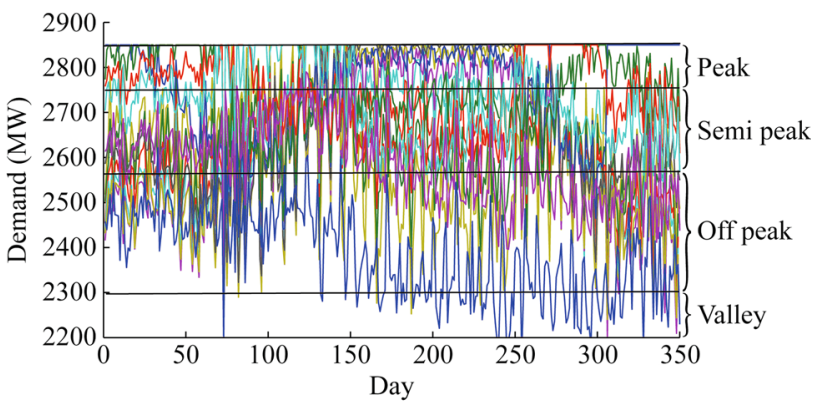

(a) Demand with discretization in four periods for one year

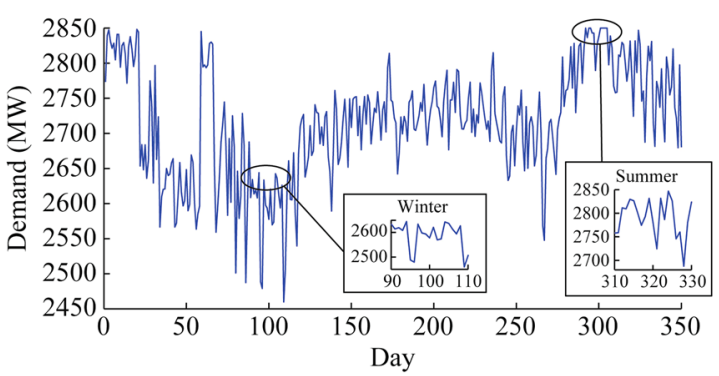

(b) Any day in peak period for one year

Fig. 1 Hourly demand for one year

The first step is to acquire energy demand data for all the nodes for one year. The second step is to identify week days and weekend days of the vector of demand. The third step is to define the total number of seasons to be analyzed and then generate the corresponding vectors. For example, using winter and summer seasons obtains four vectors of data: two for week days (winter and summer) with a total of 3120 data points for each, and two vectors for weekend days (winter and summer) with a total of 1260 data points for each. Figures $2 \mathrm{a}$ and $3 \mathrm{a}$ depict the daily demand for week days and weekend days for summer and winter, respectively. The days are arranged hourly to show the differences between distinct daily demands.

The fourth step is to use cluster techniques to determine the representative daily curve of demand for the week days and weekend days for summer and winter.

The fifth step is to use the cluster technique in [25] to group the hours of week days or weekend days by season in order to obtain a clustered-value for each hour of the twenty-four hours in a day. Figures $2 b$ and $3 b$ depict the representative daily curve for week days and weekend days obtained by season.

\section{Experimental section}

The 24 IEEE RTS is used to develop the proposed methodology. The main characteristics of transmission and generation are taken from [26]. A value of lost load (VoLL) of $1000 \$ / \mathrm{MWh}$ is considered for all nodes 


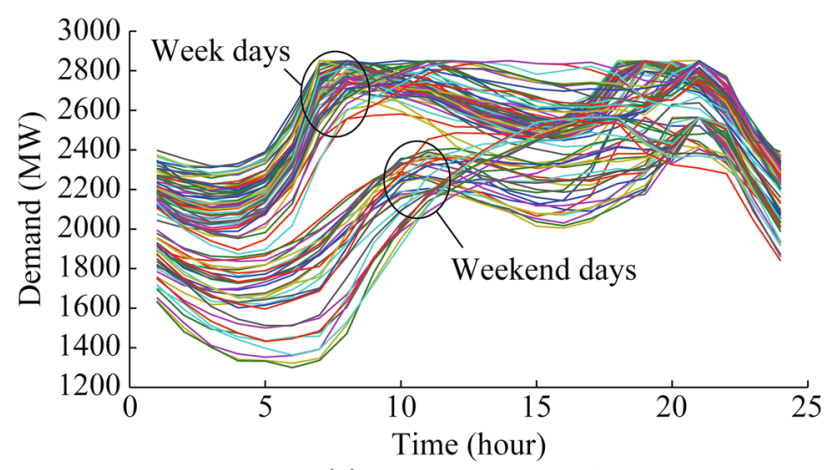

(a) Any summer week

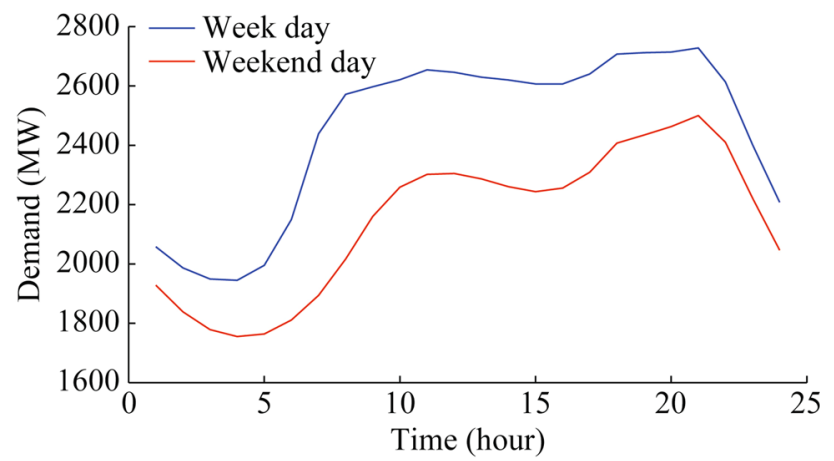

(b) Representative hourly curve for any summer day

Fig. 2 Hourly demand of summer

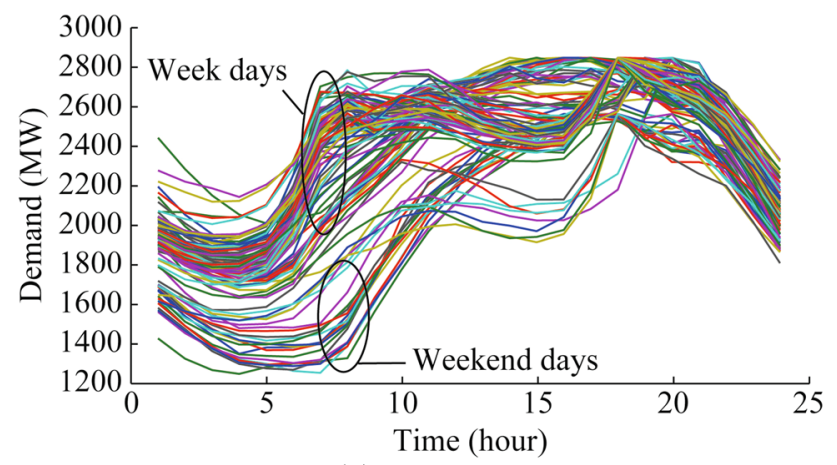

(a) Any winter week

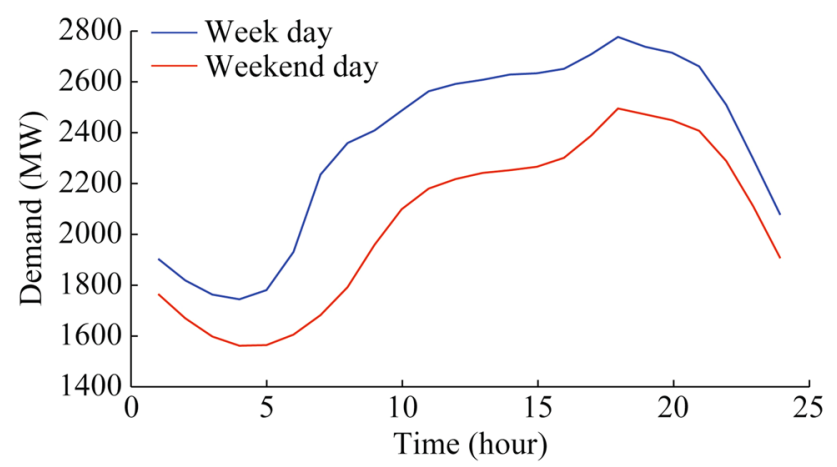

(b) Representative hourly curve for any winter day

Fig. 3 Hourly demand of winter belonging to the system [27]. The VOLL model the cost interruption service with the variable VG identifying the amount of interruption by node. To exemplify the effectiveness of the proposed methodology, all transmission lines are reduced by $25 \%$ of their flow power capacity.

A general case is considered for evaluating periods of 24 hours within a season. The demand data are obtained from [27]. Week days and weekend days are considered according to the methodology described in Section 2. Figure 4 depicts the percentage of total system load for summer (blue line) and winter (green line).

Figure 5a depicts the hours most affected by the reliability assessment. For summer week days in a 14 to 21 hour period, only $N-1$ contingencies affect the system. For time periods from 23 to 10 , only $N-2$ contingencies affect the system, due to lower demand. For summer weekend days, only $N-2$ contingencies exhibit EENS.

Figure 6 depicts the EENS for a winter season. For week days, 16:00 to 20:00 are affected by $N-1$ contingencies, and the impact for $N-2$ contingencies is mostly from 7:00 to 24:00. For weekends days, only $N-2$ contingencies exhibit EENS.

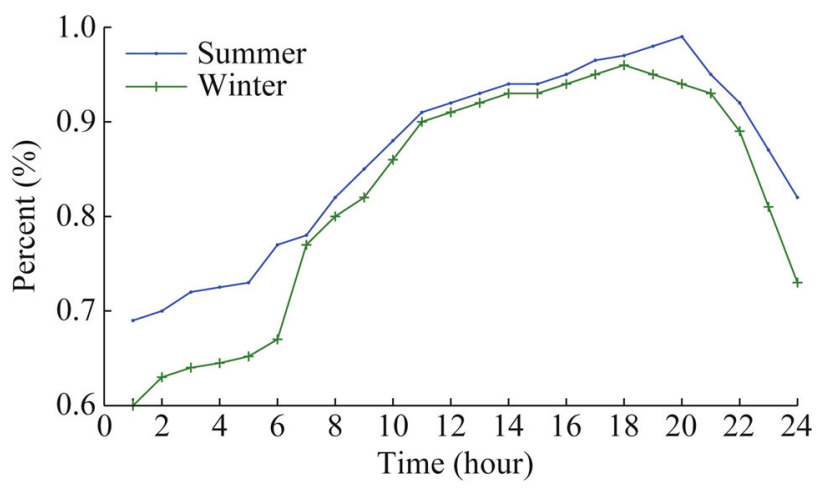

(a) Week days

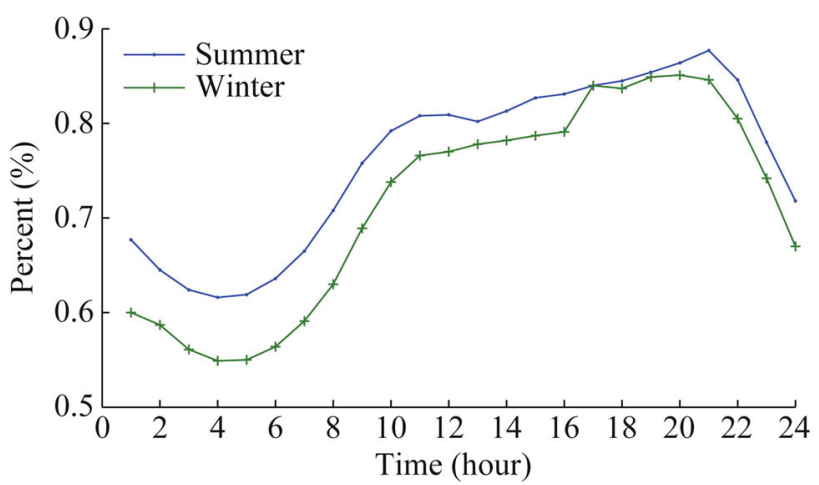

(b) Weekend days

Fig. 4 Percentage of system load for case 2 


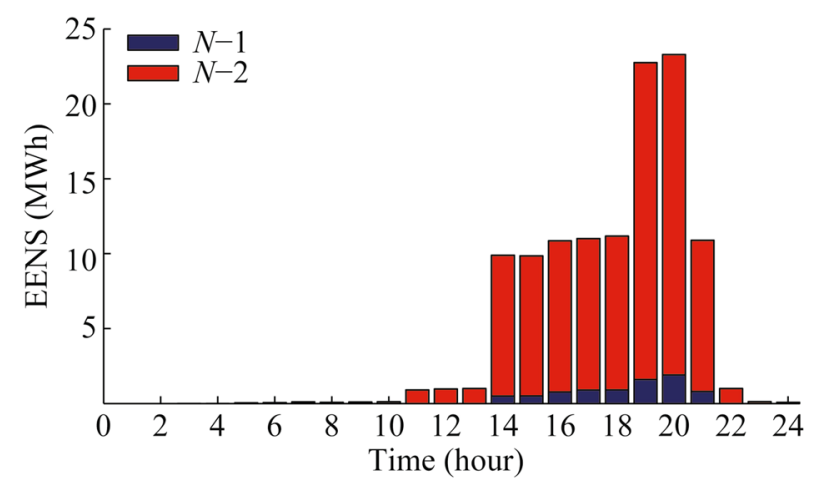

(a) Week days

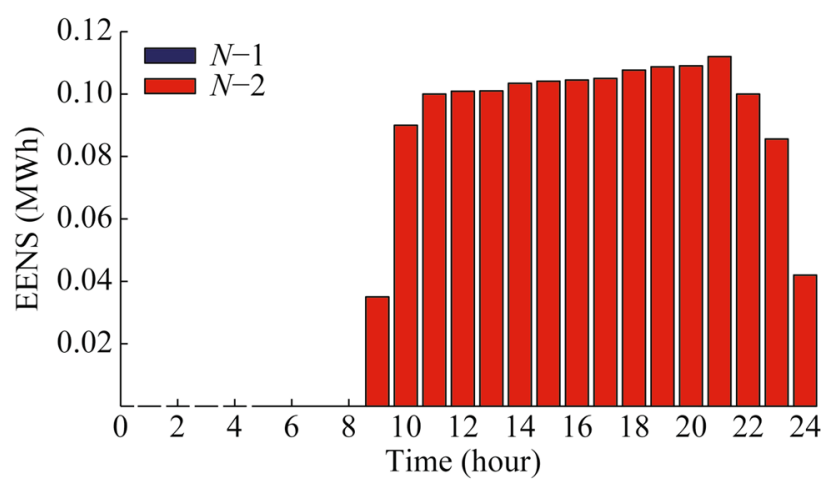

(b) Weekend days

Fig. 5 EENS without reserves for summer

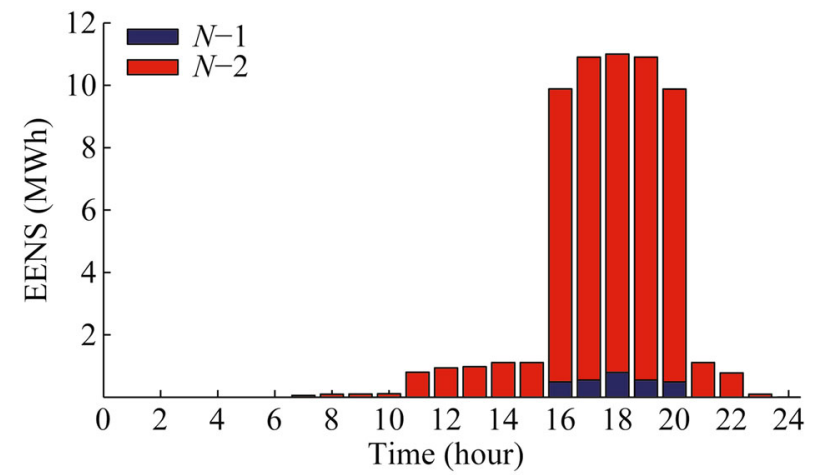

(a) Week days

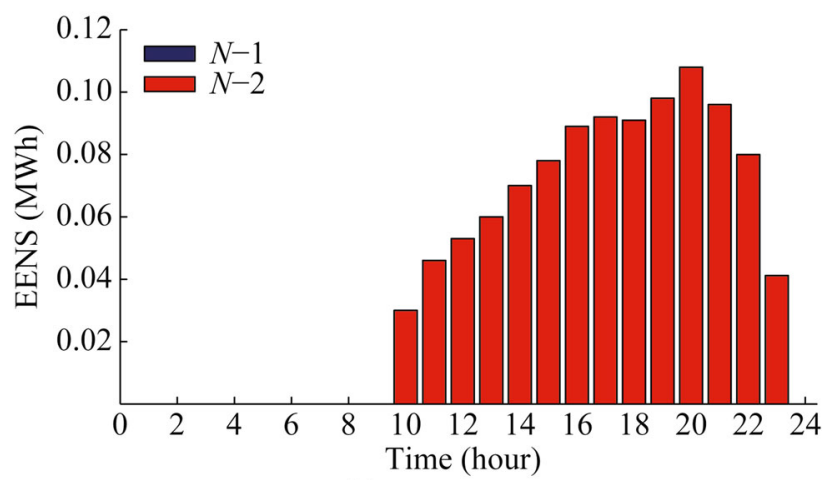

(b) Weekend days
Table 1 EENS for case 1

\begin{tabular}{llllll}
\hline Season & \multicolumn{2}{l}{ Without reserves (GW/year) } & & \multicolumn{2}{l}{ With reserves (GW/year) } \\
\cline { 2 - 3 } \cline { 5 - 6 } & $N-1$ & $N-2$ & & $N-1$ & $N-2$ \\
\hline Summer & 0.353 & 12.418 & & 0 & 7.853 \\
Winter & 0.225 & 10.803 & & 0 & 6.5 \\
\hline
\end{tabular}

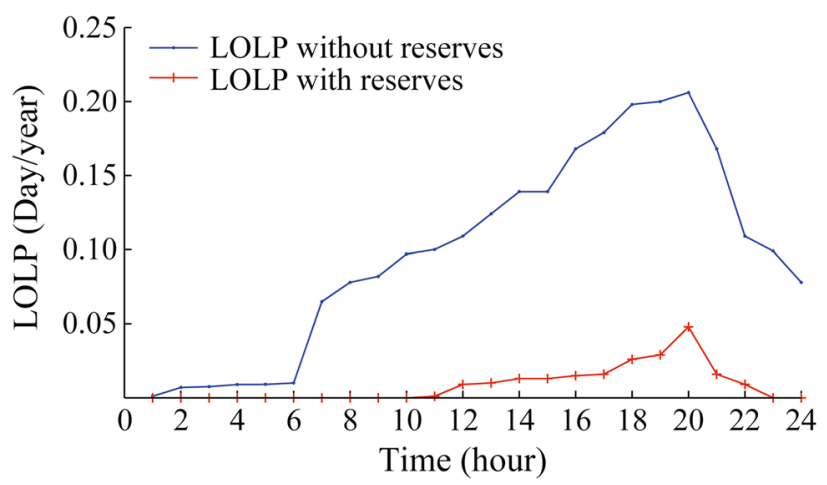

Fig. 7 LOLP system for 24 hours

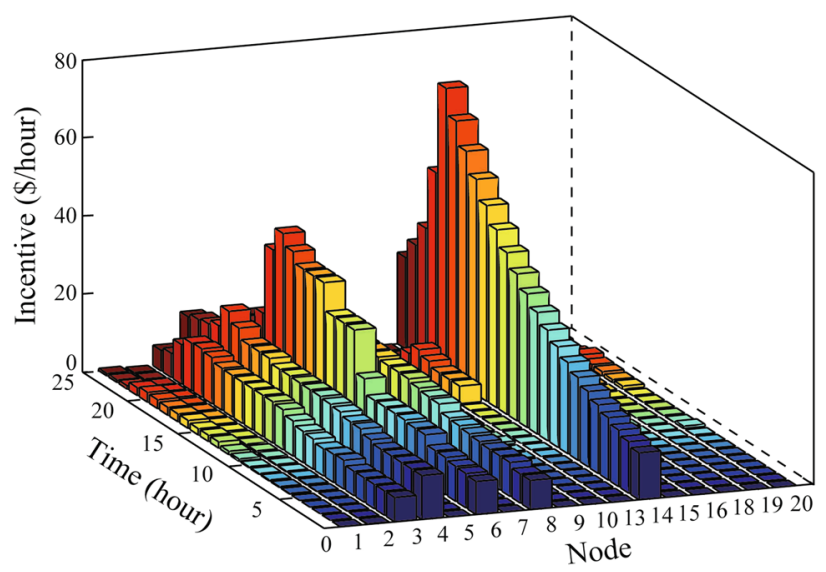

(a) Summer

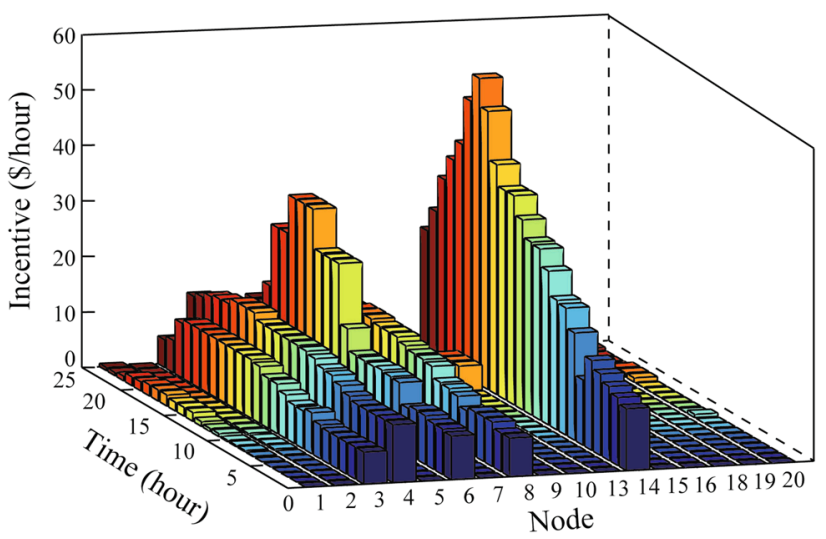

(b) Winter

Fig. 8 Incentives for week days by season

Fig. 6 EENS without reserves for winter 


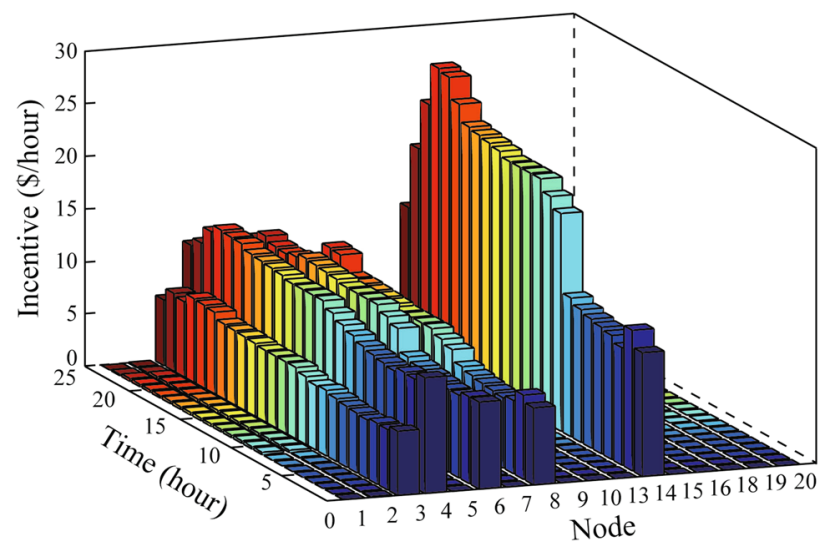

(a) Summer

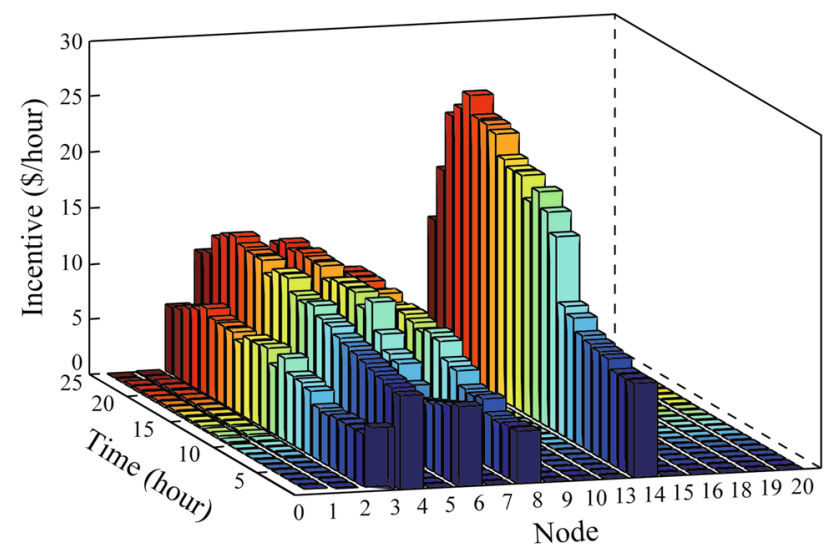

(b) Winter

Fig. 9 Incentive for weekend days by season

Table 1 lists EENS by contingency and time period. EENS is lower on weekend days than week days due to a lower demand. Energy reserve considerations help to reduce EENS to zero in $N-1$ and close to $50 \%$ in $N-2$.

Figure 7 depicts the LOLP system for 24 hours during summer. The major LOLP occurs at 20:00 without reserves, but drops significantly with the use of reserves and DR programs.

The experimental cases show that by using LOLP and ENENS within the analysis, a system operator (SO) can rapidly identify the main hours of risk for the system. The use of ENENS decomposition also avoids reliability problems arising from network congestion at peak hours, and/or unexpected increases on the demand at any time.

Figure 8 depicts the incentives for the interruptible loads within a 24 hour period during summer and winter. The incentives are calculated for nodes with load (nodes 1 to 10 , nodes 13 to 16 and nodes 18 to 20). The incentives for week days at summer are higher than during the winter. This is due to the higher summer demand. The greatest incentive is from 18:00 to 20:00, due to the presence of the peak-demand. This requires a major incentive for userparticipation.

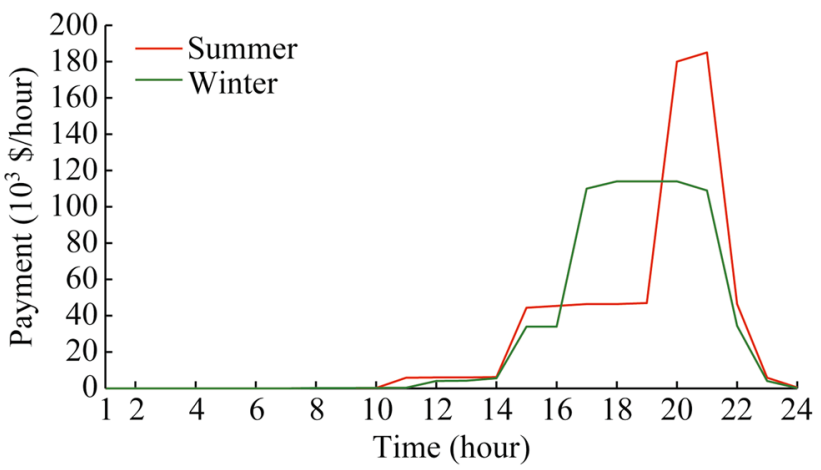

(a) Week

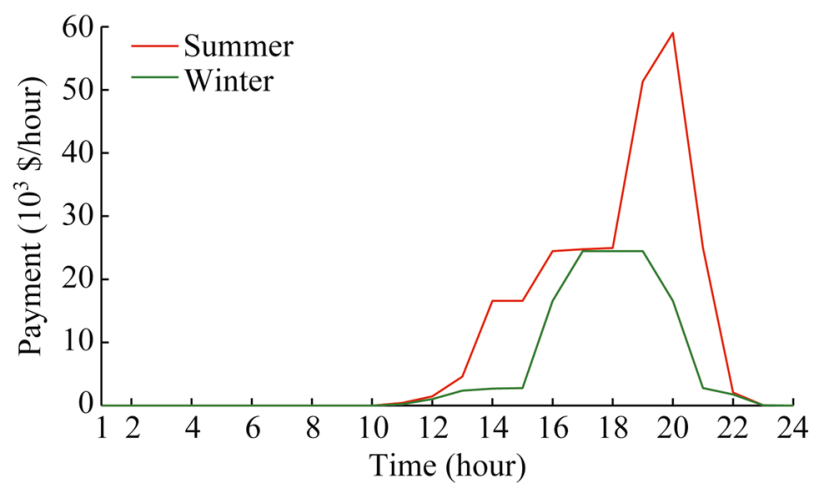

(b) Weekend

Fig. 10 Total payment system

Table 2 ENENS for node 1

\begin{tabular}{lll}
\hline Season & $\begin{array}{l}\text { Without reserves } \\
\text { (GW/year) }\end{array}$ & $\begin{array}{l}\text { With reserves } \\
\text { (GW/year) }\end{array}$ \\
\hline Summer & 1.097 & 0.406 \\
Winter & 0.73 & 0.262 \\
\hline
\end{tabular}

Figure 9 depicts the incentives for summer ( 25 \$hour) and winter (around 20 \$/hour) for weekend days. Here the incentives are reduced significantly compared with the week days incentive, due to a lower energy-demand.

Node 1 is used as an example to evaluate the impact of the methodology and calculate the INB and tariff for HR. Table 2 gives a week days curve for node 1, without reserves present an ENENS of 1.097 and $0.73 \mathrm{GW} /$ year for summer and winter respectively. Meanwhile with reserves present an ENENS of 0.406 and 0.262 GW/year for summer and winter respectively. Concluding that node 1 is one of the nodes most affected by the reliability assessment compared with other nodes. Thus, node 1 is a potential candidate for DR programs.

Figure 10 depicts the total payment system for users allowing interruptible loads by week and weekend. Observe that the highest incentive payouts do occur during peak hours.

Figure 11 depicts the ENENS decomposition, considering reserves and DR, for the summer season. The major 

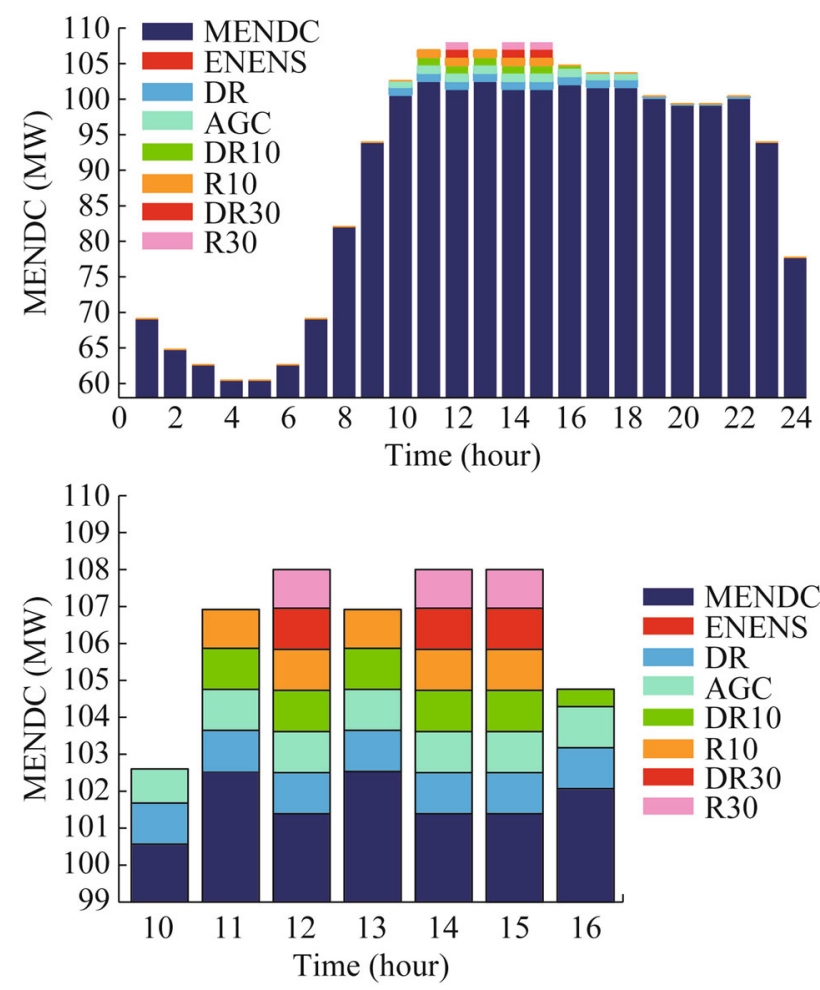

Fig. 11 MENDC and ENENS decomposition for node 1

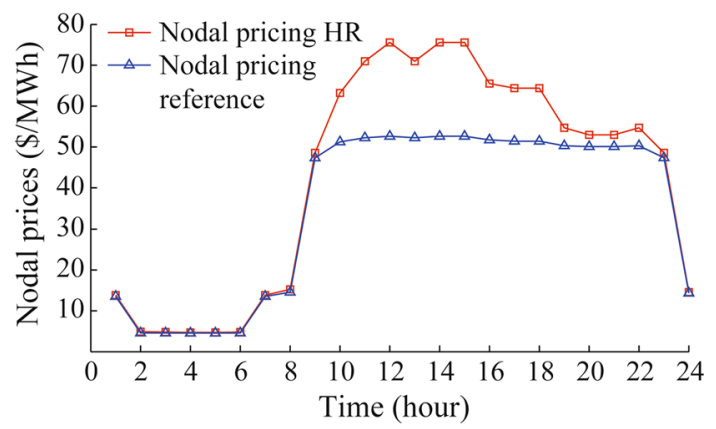

Fig. 12 Expected nodal price for summer season and week days curve

impact of contingencies $(N-2)$ is from 11 to 15 hours. The ENENS can be reduced by the use of the entire reserves and DR.

From the above results, we can observe a MENDC around $90 \%$ of the guaranteed-energy for node 1 and $10 \%$ of load available for DR programs. Note that for peak periods the ENENS is higher than in any other time.

Figure 12 depicts the expected nodal prices for summer. In this example, reserve considerations can contribute to a reduction in nodal prices mainly on week days.

Figure 13 depicts the incentive received by users at node 1. Most of the incentives for node 1 are paid for summerpeak hours. Incentives for node 1 on weekends do not vary

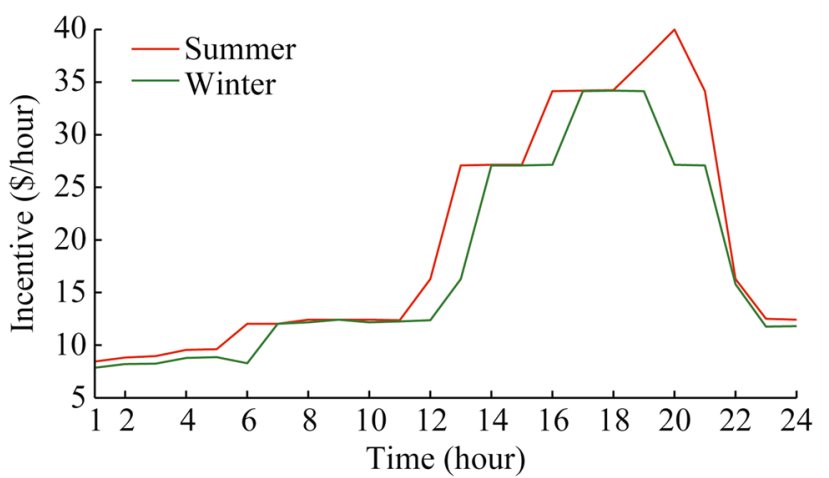

(a) Week days

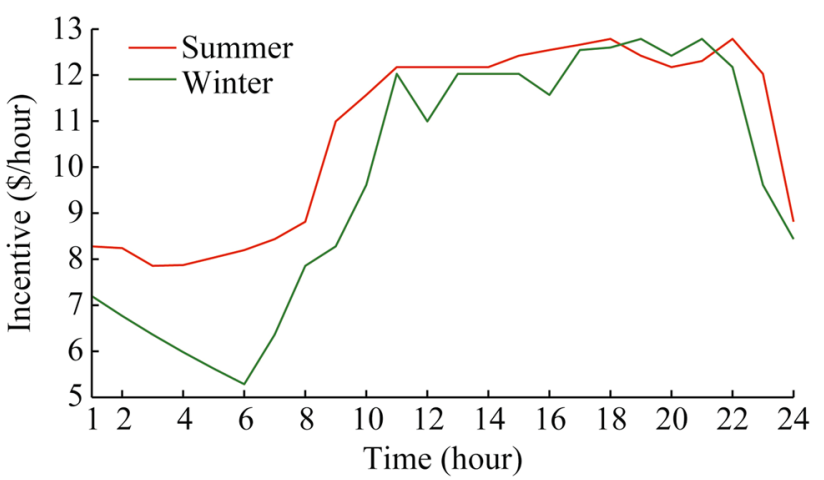

(b) Weekend days

Fig. 13 Incentives for node 1

significantly from season to season. For 10 to 22 hours, the incentive variation is around $1 \$$ /hour.

Also on weekends, since fewer important loads are connected, there is a reduced potential to apply DR programs or other types of DR, and AGC can cover most eventualities.

The next example is an automotive factory with $34 \mathrm{MW}$ of consumption [28] installed in node 1. Energy consumption depends on the number of production lines and new vehicle releases. Such consumption can be considered constant for all days due to 24-hour shifts in the factory [29]. Assuming a flat demand throughout the year, the automotive customer shows a loss of around $684900 \$$ / hour due to lack of energy in the factory [30].

Figure 14 depicts the demand consumption at node 1 for summer and winter seasons. The green area represents the energy consumption of the automotive customer for both periods; the red area represents the entire demand for weekend days; and the blue area represents the demand for week days. Energy demand is flat during winter and summer seasons.

Table 3 summarizes the automotive customer's costs for the annual consumption of electricity with normal and HR rates at node 1 . The customer's average load is $34 \mathrm{MW}$. Column fourth presents the annual consumption cost. 


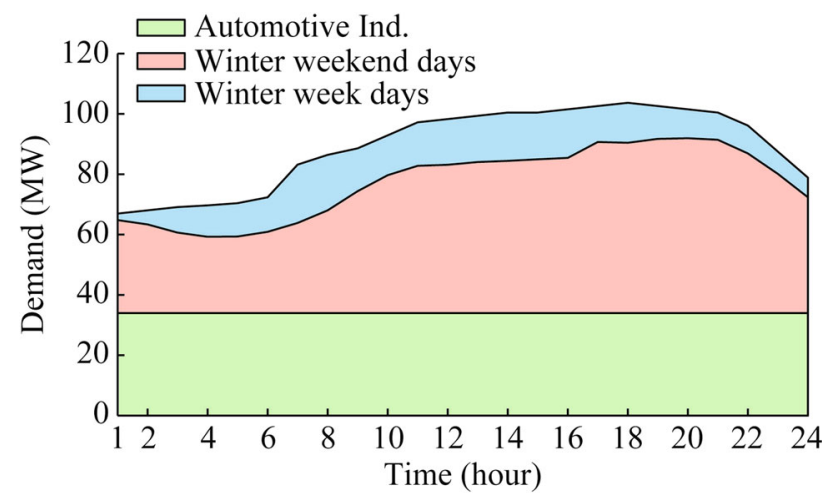

(a) Winter

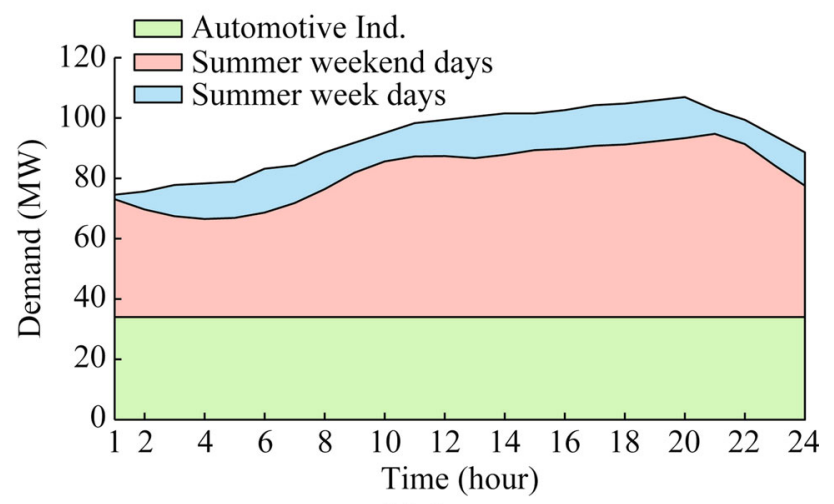

(b) Summer

Fig. 14 Demand consumption at node 1

Table 3 Summary of automotive customer for node 1

\begin{tabular}{llllll}
\hline Type & $\begin{array}{l}\text { Load } \\
(\mathrm{MW})\end{array}$ & $\begin{array}{l}\text { Annual } \\
(\mathrm{GW} / \\
\text { year })\end{array}$ & $\begin{array}{l}\text { Cost } \\
\left(10^{6} \$ /\right. \\
\text { year })\end{array}$ & $\begin{array}{l}\text { Cost HR } \\
\left(10^{6} \$ /\right. \\
\text { year })\end{array}$ & $\begin{array}{l}\text { Difference } \\
\left(10^{6} \$\right)\end{array}$ \\
\hline Automotive & 34 & 2.98 & 3.37 & 4.45 & 1.08 \\
\hline
\end{tabular}

Column fifth presents the cost of tariff HR. The last column is the difference between pay tariff HR and normal tariff.

Table 4 lists the principal contingencies on transmission lines that might occur at node 1 , with their corresponding annual costs for service interruption. The difference between pay-rates for HR and normal services is around $1.08 \times 10^{6} \$$ year. For example, node 1 presents two main interruptions annually, lasting about two hours and caused by contingencies in transmission lines. The estimated cost of each interruption is $1.37 \times 10^{6} \$$ /year ( 2 hours per 684900 \$hour). The automotive customer could avoid the extra cost by signing an uninterruptible contract at the HR tariff.

Table 5 summarizes the total costs and incentive paybacks for users in the DR and the HR programs. The summary makes it possible to estimate the annual cost by season as well as the possible INB by node. In summer, the
Table 4 Summary of contingency for node 1

\begin{tabular}{llll}
\hline Contingency & $\begin{array}{l}\text { Transient outage } \\
\text { rate per year }\end{array}$ & $\begin{array}{l}\text { Permanent outage } \\
\text { duration (hour/year) }\end{array}$ & $\begin{array}{l}\text { Cost outage } \\
\left(10^{6} \$\right)\end{array}$ \\
\hline L1-2 & 2.9 & 16 & 10.96 \\
L1-5 & 1.2 & 10 & 6.85 \\
L1-3 & 1.7 & 10 & 6.85 \\
Total & & & 24.65 \\
\hline
\end{tabular}

Table 5 Summary of annual costs at node1

\begin{tabular}{llll}
\hline Season & $\rho_{1}^{H R}\left(10^{6} \$\right)$ & $\rho_{1}^{0}\left(10^{6} \$\right)$ & $I_{N B_{1}}\left(10^{6} \$\right)$ \\
\hline Summer weekdays & 1.26 & 1.04 & 0.36 \\
Winter weekdays & 1.22 & 0.92 & 0.31 \\
Summer weekend days & 1.01 & 0.73 & 0.20 \\
Winter weekend days & 0.95 & 0.68 & 0.18 \\
Total & 4.45 & 3.37 & 1.05 \\
\hline
\end{tabular}

cost is higher due to a higher use of air conditioning and drops during the winter.

Note that the obtained results, for total annual energycosts, are really close to those of a real system. This is due to the fact that our proposed methodology uses the representative-curves of energy-demand. Also notice that the total cost difference into node 1 on an $\mathrm{HR}$ and, a regular tariff is around $1.08 \times 10^{6} \$$. The incentive payment for users willing to reduce their demand is $1.05 \times 10^{6} \$$ and, it can be covered perfectly by the difference between the HR and the regular tariffs.

\section{Conclusion}

This paper describes a practical methodology to identify interruptible loads by node in order to compensate for such energy interruptions. The compensations are carried out in accordance to IBP-DR.

The main conclusions are as follow:

1) The nodal incentives bonus is set individually according to each node interruption capacity (rate), and must be based on the difference between the reference price and the highest nodal price produced by ENNS. Hence, a higher back-payment is assigned to the nodes most affected by the contingencies on transmission lines. This is in opposition to a flat rate for all nodes in the system.

2) The incentive bonus is correlated with the electricity price and the nodal reliability, where users receive major incentives for nodes with less reliability (high ENENS), in the same way the price of reliability is higher compared to nodes with high reliability. 
3) Inclusion of an HR tariff based on reliability assessment must be carried out to satisfy customers whose manufacturing or other processes require high levels of security and reliability at their nodal point connections.

4) The estimation of a representative duration load curve is required to evaluate the impact of nodal reliability by seasons, week days, and weekend days. The curve can then be used to establish appropriate backpayments for users accepting an interruptible service as well as for those on an HR tariff.

Suggestions for further work are as follow:

1) Due to the growing of renewable energy sources, an analysis of nodal reliability is required, since it is known that this type of generation is intermittent and cannot be modeled as a conventional generator.

2) For a large systems (with 3000 buses i.e) computational effort is required, for this reason a stochastic assessment of reliability is required, especially for $N-2$ or $N-3$ contingencies analysis.

3) In this paper a traditional DC-OPF was used, but in the new literature of OPF, mathematical formulation with PTDF and LODF can be used for improve the reliability assessment, considering specific contingencies.

Acknowledgements This work was supported by Consejo Nacional de Ciencia y Tecnología (CONACyT) and Instituto Tecnológico Superior de Irapuato (ITESI).

Open Access This article is distributed under the terms of the Creative Commons Attribution 4.0 International License (http:// creativecommons.org/licenses/by/4.0/), which permits unrestricted use, distribution, and reproduction in any medium, provided you give appropriate credit to the original author(s) and the source, provide a link to the Creative Commons license, and indicate if changes were made.

\section{References}

[1] Hegazy Y, Guldmann JM (1996) Reliability pricing of electric power service: a probabilistic production cost modeling approach. Energy 21(2):87-97

[2] Wang P, Ding Y, Xiao Y (2005) Technique to evaluate nodal reliability indices and nodal prices of restructured power systems. IEE P-Gener Transm Dis 152(3):390-396

[3] Matsukawa I, Fujii Y (1994) Customer preferences for reliable power supply: using data on actual choices of back-up equipment. Rev Econ Stat 76(3):434-446

[4] Barot H, Bhattacharya K (2010) Load service probability differentiated nodal pricing in power systems. IET Gener Transm Dis 4(3):333-348

[5] Ding Y, Wang P (2006) Reliability and price risk assessment of a restructured power system with hybrid market structure. IEEE Trans Power Syst 21(1):108-116
[6] Gonzalez-Cabrera N, Gutierrez-Alcaraz G (2010) Pricing reliability service based on end-users choice. In: Proceedings of the 11th international conference on probabilistic methods applied to power systems, Singapore, 14-17 Jun 2010, p 24-29

[7] Gonzalez-Cabrera N, Gutierrez-Alcaraz G (2011) Effect assessment of demand response on nodal prices by types of classes. In: Proceedings of the 43rd North American Power Symposium (NAPS'11), Boston, MA, USA, 4-6 Aug 2011, $6 \mathrm{pp}$

[8] Wang P, Billinton R (2004) Reliability assessment of a restructured power system considering the reserve agreements. IEEE Trans Power Syst 19(2):972-978

[9] Mehrtash A, Wang P, Goel L (2013) Reliability evaluation of restructured power systems using a novel optimal power-flowbased approach. IET Gener Transm Dis 7(7):192-199

[10] Wu Q, Wang P, Goel L (2010) Direct load control (DLC) considering nodal interrupted energy assessment rate (NIEAR) in restructured power systems. IEEE Trans Power Syst 25(3):1449-1456

[11] Babar M, Ahamed TPI, Al-Ammar EA, Shah A (2013) A novel algorithm for demand reduction bid based incentive program in direct load control. Energy Procedia 42:607-613. doi:10.1016/j. egypro.2013.11.062

[12] Sullivan M, Bode J, Kellow B, Woehleke S, Eto J (2013) Using residential AC load control in grid operations: PG\&E's ancillary service pilot. IEEE Trans Smart Grid 4(2):1162-1170

[13] Xiang Y, Liu J, Yang W, Huang C (2015) Active energy management strategies for active distribution system. J Mod Power Syst Clean Energy 3(4):533-543. doi:10.1007/s40565-0150159-2

[14] Chao HP, Wilson R (1987) Priority service: pricing, investment, and market organization. Am Econ Rev 77(5):899-916

[15] Zakariazadeh A, Jadid S, Siano P (2014) Smart microgrid energy and reserve scheduling with demand response using stochastic optimization. Int J Elec Power 63:523-533. doi:10. 1016/j.ijepes.2014.06.037

[16] Gong Y, Cai Y, Guo Y, Fang Y (2016) A privacy-preserving scheme for incentive-based demand response in the smart grid. IEEE Trans Smart Grid 7(3):1304-1313

[17] Ullah I, Javaid N, Khan ZA, Qasim U, Khan ZA, Mehmood SA (2015) An incentive-based optimal energy consumption scheduling algorithm for residential users. Procedia Comput Sci 52:851-857. doi:10.1016/j.procs.2015.05.142

[18] Abdi H, Dehnavi E, Mohammadi F (2016) Dynamic economic dispatch problem integrated with demand response (DEDDR) considering non-linear responsive load models. IEEE Trans Smart Grid 7(6):2586-2595

[19] Osorio K, Sauma E (2015) Incentive mechanisms to promote energy efficiency programs in power distribution companies. Energy Econ 49:336-349. doi:10.1016/j.eneco.2015.02.024

[20] Theristis M, Papazoglou IA (2014) Markovian reliability analysis of standalone photovoltaic systems incorporating repairs. IEEE J Photovolt 4(1):414-423

[21] Zhao Q, Wang P, Goel L, Ding Y (2013) Impacts of contingency reserve on nodal price and nodal reliability risk in deregulated power systems. IEEE Trans Power Syst 28(3):2497-2506

[22] Reliability standards for the bulk electric systems of North America. North American Electric Reliability Corporation (NERC), Atlanta, GA, USA, 2010

[23] Ela E, Milligan M, Kirby B (2011) Operating reserves and variable generation. National Renewable Energy Laboratory (NREL), Golden, CO

[24] Stott B, Jardim J, Alsaç O (2009) DC power flow revisited. IEEE Trans Power Syst 24(3):1290-1300 
[25] Gil E, Aravena I, Cárdenas R (2015) Generation capacity expansion planning under hydro uncertainty using stochastic mixed integer programming and scenario reduction. IEEE Trans Power Syst 30(4):1838-1847

[26] Grigg C, Wong P, Albrecht P, Allan R, Bhavaraju M, Billinton R, Chen Q, Fong C, Haddad S, Kuruganty S, Li W (1999) The IEEE reliability test system-1996: a report prepared by the reliability test system task force of the application of probability methods subcommittee. IEEE Trans Power Syst 14(3): $1010-1020$

[27] The value of lost load (VoLL) for electricity in Great Britain. Final report for OFGEM and DECC. London Economics, London, UK, 2013

[28] Sullivan JL, Burnham A, Wang M (2010) Energy-consumption and carbon-emission analysis of vehicle and vomponent manufacturing. Argone National Laboratory, Argone IL

[29] Carrillo J (2012) Productividad, ingresos y trabajo en la industria automotriz de mexico, Seminrario de Ingresos y productividad en America del norte comision para la coperacion laboral, Cap 9, pp 197-244. http://www.colef.mx/jorgecarrillo/wp-content/ uploads/2012/04/PU209.pdf
[30] Fysikopoulos A, Anagnostakis D, Salonitis K, Chryssolouris G (2012) An empirical study of the energy consumption in automotive assembly. Procedia CIRP 3:477-482

Nestor GONZÁLEZ-CABRERA received the B.S. in Electrical Engineering of University of Guanajuato (UG) in 2008. In 2011 obtained the degree of Master in Science from the Graduate Program and Research in Electrical Engineering (PGIIE) of the Technological Institute of Morelia (ITM) is currently pursuing the Ph.D. degree at PGIIE of ITM, and is part of the Electro mechanic engineering department in Superior Technological Institute of Irapuato (ITESI). His research interests are operation and control of electrical power systems.

Guillermo GUTIÉRREZ-ALCARAZ received the B.Sc. and M.Sc. degrees from the ITM, Morelia, Mexico, and Ph.D. degree from Iowa State University, Ames Iowa, USA, all in Electrical Engineering. $\mathrm{He}$ has been a member of PGIIE-ITM since 1996. His main areas of interest are the operation and control of electrical power systems and distribution systems and electricity markets. 